\title{
Sustainability of concrete using recycled aggregate: a review.
}

\section{Sustantabilidad del concreto usando agregados reciclados: una revisión.}

\author{
Mohammad Umar Khan ${ }^{1}$, Dr. Manju Dominic ${ }^{2}$ \\ ${ }^{1}$ M.Tech scholar, ${ }^{2}$ Professor \\ School of Civil Engineering,Galgotias University \\ Gr. Noida, Uttar Pradesh, India
}

Corresponding author mail id: mohammadumar.khan@galgotiasuniversity.edu.in

\begin{abstract}
Sustainable development is essential to the well-being of our planet, human development, and the continued growth of society. As we know, concrete are the most commonly used substance in the world, after water. However, recycled concrete is the biggest advantage for us. Nowadays the construction industry also tries to replace the virgin material to reduce the environmental impact, global warming, pollution, etc. The construction activity and old structural building also is an issue for the environment. The reuse and recycle of concrete would therefore also reduce the burden on the environment. So this paper will give a summary of recycled concrete aggregate, their sustain on the environment, properties of the application of recycled aggregate, and the resultant of their properties of recycled concrete aggregate.

Keywords- Aggregate, Concrete, Construction Development, Environment, Recycled, Sustainable.

\section{RESUMEN}

El desarrollo sostenible es esencial para el bienestar de nuestro planeta, el desarrollo humano y el crecimiento continuo de la sociedad. Como sabemos, el hormigón es la sustancia más utilizada en el mundo, después del agua. Sin embargo, el hormigón reciclado es la mayor ventaja para nosotros. Hoy en día la industria de la construcción también intenta reemplazar el material virgen para reducir el impacto ambiental, el
\end{abstract}


Sustainability, Agri, Food and Environmental Research, (ISSN: 0719-3726), 10(X), 2022: http://dx.doi.org/

calentamiento global, la contaminación, etc. La actividad de la construcción y la construcción de estructuras antiguas también es un problema para el medio ambiente. Por tanto, la reutilización y el reciclaje del hormigón también reduciría la carga sobre el medio ambiente. Por lo tanto, este artículo dará un resumen del agregado de concreto reciclado, su sustento en el medio ambiente, las propiedades de la aplicación del agregado reciclado y el resultado de sus propiedades del agregado de concreto reciclado.

Palabras clave- Agregado, Concreto, Desarrollo constructivo, Medio ambiente, Reciclado, Sostenible.

\section{INTRODUCTION}

The concept of sustainable development in the engineering field provides multiple possibilities for the use of recycled aggregates. The increase in population, the development of urbanization, and industrialization directly affect the increase in the consumption of various materials and energy, therefore, the increase in amount of solid waste. The use of recycled concretes as an aggregate in structural concrete has attracted more and more attention, and recent studies have studied its performance (Yong et.al,2009). "Old concrete" refers to waste concrete used for the manufacturing of recycled aggregates, while "recycled concrete" refers to new concrete manufactured from recycled aggregates. "Recycled aggregate" refers to aggregate produced by old concrete crushing, while "natural aggregate" refers to modern aggregate created by natural stone crushing. (Katz et.al,2012). Therefore, it is particularly important to implement the well-known "3R" principle (reduce, reuse, recycle) in this field. The goal is to reduce energy consumption and pollution levels (reduce), reuse old concrete as aggregate to produce new (reuse), and recycle concrete (recycle) .

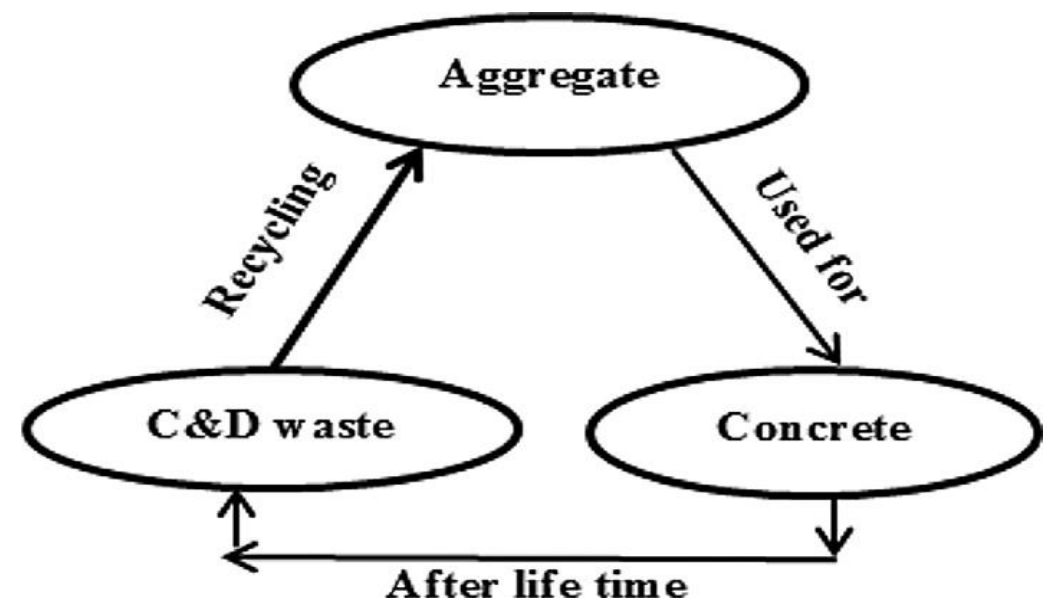

Fig 1 : Schematic representation of recycling technique 
Sustainability, Agri, Food and Environmental Research, (ISSN: 0719-3726), 10(X), 2022: http://dx.doi.org/

\section{MATERIALS}

\section{RECYCLED AGGREGATE}

Recycled aggregates produced from aged concrete that has been dismantled and removed from the structure into fractions of various sizes (Tushar et.al,2014). The aggregate commonly processed by the grinding of parent or aged concrete, such as collapsed waste concrete, is recycled concrete aggregate (RCA). The basic technique behind the recycling process involves smashing demolished concrete to create pieces of smaller sizes by subjecting various screening and sorting stages to a series of performance ( Behera et.al,2012).

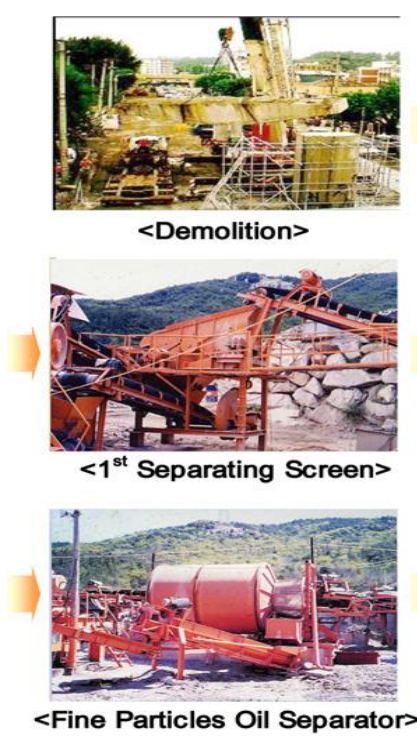

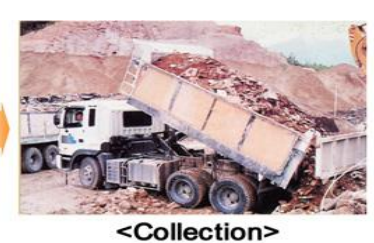

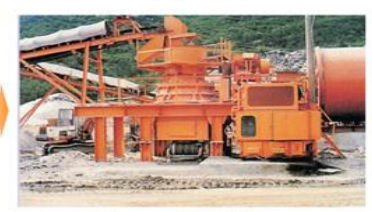

<Cone Crushing >

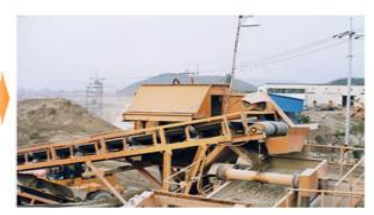

<Air Blow Separator>

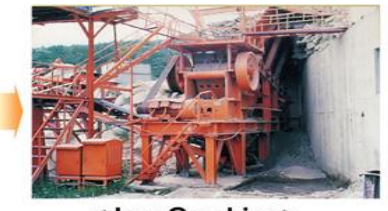

<Jaw Crushing>

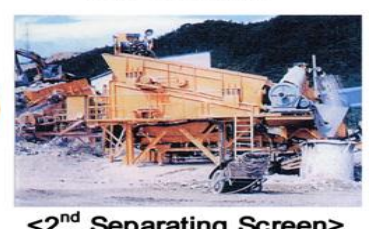

$<2^{\text {nd }}$ Separating Screen $>$

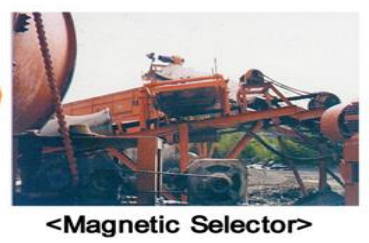

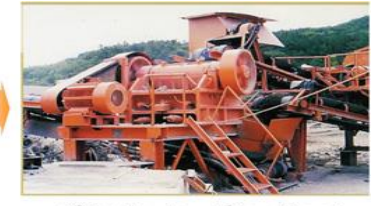

<Single Jaw Crushing>

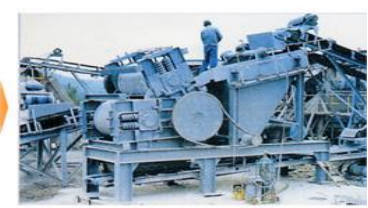

<Roll Crushing>

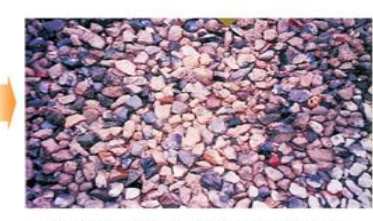

<Recycled Aggregate>

Fig 2. Recycled aggregate manufacturing process

\section{PROPERTIES}

Recycled aggregates usually have higher water absorption and lower specific gravity. The density of rca is lower than that of ordinary aggregate (Yong et.al, 2009). The recycled aggregate is also more heterogeneous and porous and contains a lot of impurities. Its characteristic is that compared with natural aggregate, the compressive strength of recycled concrete aggregate with the more water absorption rate is reduced. The higher the proportion of recycled aggregate, the better the fluidity of the concrete. Concerning the natural aggregate, the effect and wear resistance of the rca is lower; this is also because of the presence of a porous mortar layer around the recycled aggregate grain, which spreads and crushes more easily . 


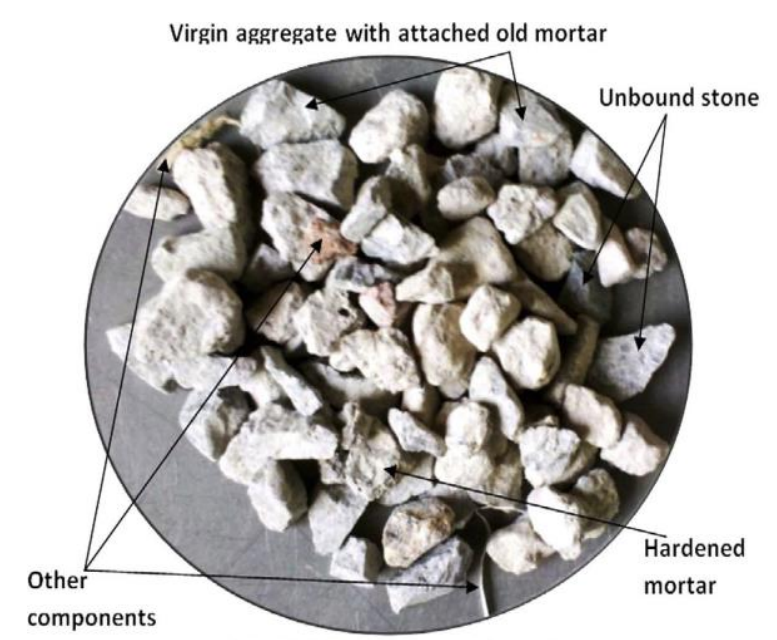

(a) $R A$ from recycling plant

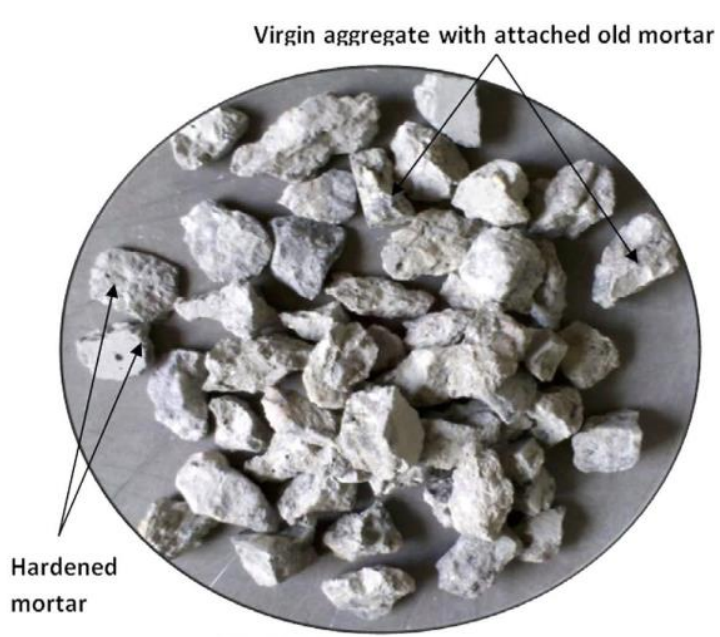

(b) $R A$ from laboratory

Fig 3. Recycled aggregates from different sources

\section{NATURAL AGGREGATE}

Natural aggregate, i.e. fine aggregate and coarse aggregate. A dimensionless value used to calculate the aggregate volume of concrete mixes is the aggregate specific gravity. The aggregate moisture content is the amount of water present either within pores or on the surface in a sample of aggregate. Aggregate absorption is the weight of water in aggregate pores, calculated as a percentage of dry aggregate weight. The aggregate sieve analysis involves evaluating the coarse and fine aggregate by using a collection of sieves(Mohd. Arafa et.al,2017).

\section{WATER-CEMENT RATIO}

The generally cement used in concrete is ordinary Portland cement. The watercement lies from .4 to .6. Fined Recycled aggregate lowered the compressive strength and improved the drying shrinkage of the concrete with a fixed water-cement. But despite the use of a lower free W / C, the use of Fined Recycled aggregate led to a decrease in compressive power. This may be due to the weaker mechanical properties of Fined Recycled aggregate that are intrinsic.

\section{RECYCLED CONCRETE AGGREGATES}

It is composed of relatively smooth unbroken stone blocks, mortar or angular blocks of the mortar itself adhered to the stone, and angular blocks of crushed stone. Negative effects on the quality of recycled concrete aggregate, such as reduced 
Sustainability, Agri, Food and Environmental Research, (ISSN: 0719-3726), 10(X), 2022: http://dx.doi.org/

compressive strength, tensile strength due to increased concrete porosity, and weak aggregate-matrix interface bonds. Its characteristic is that compared with natural aggregate, the compressive strength of recycled concrete aggregate with a more water absorption rate is reduced. RCA has a lower stiffness, shows a smaller decrease in tensile or compressive strength, and shows a strong decrease in fracture energy and fracture zone duration (Casuccio,2008). The absorption ability of the recycled aggregates determines the functionality of recycled aggregate concrete (Etxeberria et. al, 2007).

\section{PROPERTIES}

The destroyed concrete consists of crushed stone aggregate adhering to it with old mortar, with water absorption ranging from $1.5 \%$ to $7.0 \%$, which is relatively higher than that of normal aggregates. The higher the proportion of recycled aggregate, the better the fluidity of the concrete. The recycled aggregate bulk density is smaller than that of natural concrete aggregate. The contribution of mineral admixtures is higher than that of natural aggregate concrete to improve the production of recycled aggregate concrete.

\section{ADVANTAGES OF RECYCLED CONCRETE}

- Used for precast \& cast in situ construction.

- Economic: - There are no detrimental effects on concrete $\&$ it is expected that the increase in the cost of cement could be offset by the lower cost of RCA.

- Save environment: - There is no uncovering of natural assetsand less transportation. Also less land is utilised.

- $\quad$ Save time: - There is no hanging tight for material accessibility.

- Less outflow of carbon because of less smashing.

- Up to $25 \%$ supplanting of natural assets with RCA or recycled mixed aggregates (RMA) without a requirement for extra testing for all concrete up to a characteristic strength of $65 \mathrm{MPa}$. As per standard, is allowed.

- Reduce the impact of squander materials on environment in terms of dust particles, disposed etc.

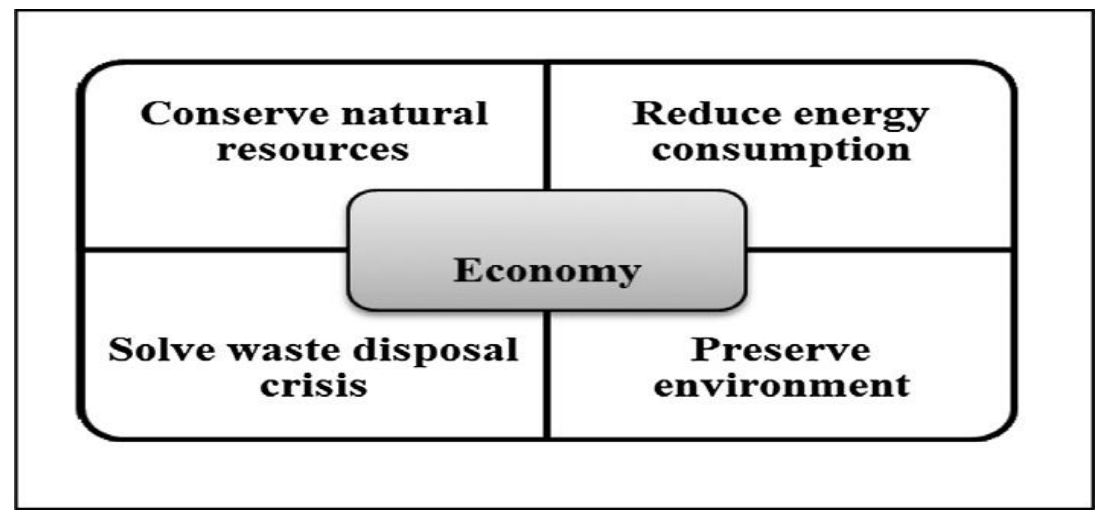

Fig 4: Benefits of recycling of C\&D waste 
Sustainability, Agri, Food and Environmental Research, (ISSN: 0719-3726), 10(X), 2022: http://dx.doi.org/

\section{DISADVANTAGES OF RECYCLED CONCRETE}

- Less quality (for example. compressive strength diminished by 10-30\%).

- Duration of acquirement of materials may influence life pattern of project.

- Land, exceptional equipment's machineries and wind blowers are required (more cost).

- Very high water assimilation (up to $6 \%$ ).

- $\quad$ It have more drying shrinkage \& creep.

- $\quad$ Man power used in the production need more carefulness.

- $\quad$ Sometime due to dust it cause respiratory problems to the workers involves in production.

\section{TESTING AND STRENGTH}

\section{SLUMP TEST}

The slump of prepared fresh concrete was measured utilizing the regular slump test apparatus. The quantity required for the slump test of fresh concrete was taken aside on a steel plate when a fresh concrete mixture was first prepared, around 20 I ( 3 times). The first downturn (initial) was assessed. Slump values were then routinely calculated at intervals of 15 minutes. Between the measurement periods, plastic films protected the concrete mixtures. The average testing time lasted 165 minutes (Poon et. al, 2004). The higher proportion of recycled aggregates continued to increase the fresh concrete slump (Kyuhun et.al.,2013).

\section{COMPRESSIVE TEST AND STRENGTH}

Compressive strength was calculated after 3, 7, 28, 56, 90, 180 days. These cubes were taken out from the molds after 1 Day and were healed at $27^{\circ} \mathrm{C}$ in water before examination. The different distribution of particles from higher concrete strength groups, which at the last of the crushing process are less friable and thus coarser, so that they are present in higher percentages in the coarse fraction rather than in the finer coarse recycled-aggregate fraction. At an early age, the increase in cube compressive strength, particularly for RCA specimens, was higher than at older ages. Under the wet healing situation, the cube compressive power of control concrete was around 47.6 percent higher on average than that of RCA (MostafaKazemi,2019). Recycled brick aggregates have a low W / C and offer improved performance compared to high W / C in terms of concrete compressive strength (Mohammed et.al, 2014). Coarse aggregate strength are the most important parameters of the aggregate that affect compressive strength. 
Sustainability, Agri, Food and Environmental Research, (ISSN: 0719-3726), 10(X), 2022: http://dx.doi.org/

\section{TENSILE TEST AND STRENGTH}

The tensile breaking of concrete strengths from age's upto3, 7,28,56,90,180 days. The splitting tensile strengths of rca are greater than those of natural aggregate tensile splitting strengths. This increase could be due to the high quality of recycled washed aggregates and the continued operability of concrete mixtures (Ozgur Cakir\& Omerozkan Sofyanli,2014). As the proportion of recycled aggregates increased, the splitting tensile strength of concrete typically decreased (Kyuhun Ki \& Myoungsu Shin,2013). Recycled concrete's aggregate tensile strength is therefore slightly less than that of natural aggregate concrete (Faiz et.al ,2013). The other theoretically inferior mechanical property of Recycled concrete aggregateare the split tensile strength that, with the growth in recycled aggregate quantity, exhibits similar behavior as compressive strength (Behera et.al,2012).

\section{CONCLUSIONS}

High compressive strength, tensile strength and bending strength can be obtained from RCA. Recycled aggregate collected from on-site tested concrete cubes (RCA) shows good promise as a coarse aggregate for new concrete production. (Yong \& Teo,2009) Especially if a finer coarse recycled aggregates are used, a lower shrinkage strain can be found, especially for an earlier curing time. The last aspect (considered with the lower modulus of elasticity) indicates a less tendency to crack in recycled concrete. Recycled aggregate coarse concrete and natural aggregate concrete are close to each other in their flexural strength and cubic compressive strength (Chen et.al,2018). According to the results of this study, aggregates with aggregates in (received) state and with a recycled aggregate content of not high than $50 \%$ should be the best for the production of normalstrength recycled aggregate concrete. Recycled aggregate concrete's compressive strength decreases at any given exposure temperature as the proportion of recycled concrete aggregate increases (Poon et.al 2004]. Using recycled aggregates in concrete can save the natural source of stone and produce greener concrete for construction. Compared to its counterpart control concrete, the elastic modulus of rca measured at both elevated temperatures is not significantly decreased. The compressive strength of RCA specimens under the impact loadings increases as the strain intensity increases. With the rise in RCA replacement \% in general, compressive strength of RAC at more strain rates decreases, \& the strength values start to differ when RCA replacement \% exceeds $50 \%$, which is close to the quasi-static state situation (Jianz huang \& Long Li,2015). 
Sustainability, Agri, Food and Environmental Research, (ISSN: 0719-3726), 10(X), 2022: http://dx.doi.org/

\section{REFERENCES}

Berndt, M.L,(2009) ,Properties of sustainable concrete containing fly ash, slag and recycled concrete aggregate Exhibition St., Melbourne, Victoria 3000, Australia pg (2607-2613).

Amnon Katz (2002), Properties of concrete made with recycled aggregate from partially hydrated old concrete National Building Research Institute, Department of Civil Engineering, Technion, Israel Institute of Technology, Haifa 32000.

Dragica JEVTIĆ, \& others (2012) Achieving Sustainability of Concrete by Recycling Of Solid Waste Materials. Volume 1, 22-39,2012

Yong P.C, Teo, D.C.L (2009) ,Utilization of Recycled Aggregates as Coarse Aggregate in Concrete UNIMAS E-Journal of civil engineering, vol 1/August

Valeria Corin aldesi Mechanical and elastic behaviour of concretes made of recycledconcrete coarse aggregates learning Università Politecnica delle Marche, Ancona, Italy pg(1616-1620)

Fangming Deng, Yigang He, Shuangxi Zhou, Yun Yu, Haigen Cheng, Xiang Wu Compressive strength prediction of recycled concrete based on deep

Zong-ping Chen, Kai-wang Huang, Xiang-gang Zhang, Jian-yang Xue ,(2018), Experimental Research on the Flexural Strength of Recycled Coarse Aggregate concrete learning ,pp 562-569

Poon, C.S, Shui, Z.H, \& others, (2004), Influence of moisture states of natural and recycled aggregates on the slump and compressive strength of concrete Hong Kong Polytechnic University, Kowloon, Hong Kong, China pg 31-36

Mostafa Kazemi, \& others,(2019), Compressive strength assessment of recycled aggregate concrete using Schmidt rebound hammer and core testing.pg 630-638

TarekUddin Mohammed, \& others ,(2014), Recycling of Brick Aggregate Concrete as Coarse Aggregate, American Society of Civil Engineers.

Jongsung Sim, Cheolwoo Park, (2011). Compressive strength and resistance to chloride ion penetration and carbonation of recycled aggregate concrete with varying amount of fly ash and fine recycled aggregate ,2352-2360

Mohd. Arafa, Bassam A. Tayeh, (2017),Investigating the Effect of Sulfate Attack on Compressive Strength of Recycled Aggregate Concrete, Islamic University of Gaza, Gaza, Palestine volume 4, issue 4.

Casuccio, M.,(2008), Failure mechanism of recycled aggregate concrete. 1500-1506 
Sustainability, Agri, Food and Environmental Research, (ISSN: 0719-3726), 10(X), 2022:

http://dx.doi.org/

Ozgur Cakir, Omer ozkan Sofyanli, (2014). Influence of silica fume on mechanical and physical properties of recycled aggregate concrete Yıldız Technical University, 34210 Istanbul, Turkey.

Kyuhun Ki, Myoungsu Shin, Soowon Cha, (2013), Combined effects of recycled aggregate and fly ash towards concrete sustainability, 499-507

Hammad Salahuddin, Adnan Nawaz, et al., (2019) Effects of elevated temperature on performance of recycled coarse aggregate concrete COMSATS University Islamabad, Pakistan, 415-425

Shi-cong Kou, Chi-sun Poon, Francisco Agrela, (2011),Comparisons of natural and recycled aggregate concretes prepared with the addition of different mineral admixtures Cement \& Concrete Composites 33, 788-795

Faiz Uddin Ahmed Shaikh, Mechanical properties of concrete containing recycled coarse aggregate at and after exposure to elevated temperatures, curtin university, perth , Australia, july 2017

Abdelkader Hammoudi, Karim Moussaceb ,(2019),Comparison of artificial neural network (ANN) and response surface methodology (RSM) prediction in compressive strength of recycled concrete aggregates, 425-436

Jianzhuang Xiao, Long Li, \& others ,(2015)Compressive behaviour of recycled aggregate concrete under impact loading, 46-55

Faiz Uddin Ahmed Shaikh, et al., (2013) Journal of Sustainable Cement-Based Materials curtin university, perth, Australia.

Eduardus A.B. Koenders, et al., (2014),Compressive strength and hydration processes of concrete with recycled aggregates , 203-212

Etxeberria, M., Vázquez, E., Marí, A.,Barra, M.,(2007), Influence of amount of recycled coarse aggregates and production process on properties of recycled aggregate concrete 735-742

Kou Shi-Cong, Poon Chi-Sun, (2009), Properties of concrete prepared with crushed fine stone, furnace bottom ash and fine recycled aggregate as fine aggregates The Hong Kong Polytechnic University, Hung Hom, Hong Kong, China,2877-2886

Ridzuan, A.R.M., et al., (2011). The influence of recycled aggregate on the early compressive strength and drying shrinkage of concrete ,pg 1455-1422

Wai Hoe Kwan, Mahyuddin Ramli, et al.,2012, Influence of the amount of recycled coarse aggregate in concrete design and durability properties University Sains Malaysia, Pulau Pinang, Malaysia ,565-573 
Sustainability, Agri, Food and Environmental Research, (ISSN: 0719-3726), 10(X), 2022:

http://dx.doi.org/

Chakradhara, Rao,M., et al., (2010), Influence of field recycled coarse aggregate on properties of concrete

Tushar, R, et al., (2014), Use of Recycled Aggregate Concrete The Hong Kong Polytechnic University, Hung Hom, Kowloon, Hong Kong, 19-29

Monalisa Behera \& others,(2012) Recycled aggregate from C\&D waste \& its use in concrete-A breakthrough towards sustainability in construction sector:A review,American Society of Civil Engineers

Pradeep Kumar Gautam\& others,(2015) Sustainability in civil construction and the role of civil engineers, Volume 3

Received: $15^{\text {th }}$ February 2021; Accepted: $12^{\text {th }}$ April 2021; First distributed: $30^{\text {th }}$ April 2021 